Review Article

\title{
Mechanistic Understanding of the Engineered Nanomaterial- Induced Toxicity on Kidney
}

\author{
Haiyang Zhao, ${ }^{1,2}$ Luxin Li, ${ }^{1,3}$ Huilu Zhan, ${ }^{1,2}$ Yanhui Chu $\mathbb{D}^{3}{ }^{3}$ and Bingbing Sun $\mathbb{D}^{4}$ \\ ${ }^{1}$ Institute of Life Sciences, Biomedical Collaborative Innovation Center of Zhejiang province, Wenzhou University, 325035 Wenzhou, \\ Zhejiang, China \\ ${ }^{2}$ School of Pharmaceutical Sciences, Wenzhou Medical University, 325035 Wenzhou, China \\ ${ }^{3}$ Heilongjiang Key Laboratory of Tissue Damage and Repair, Medical Research Center, Mudanjiang Medical University, \\ Heilongjiang 157011, China \\ ${ }^{4}$ State Key Laboratory of Fine Chemicals, Dalian University of Technology, 2 Linggong Road, 116024 Dalian, China
}

Correspondence should be addressed to Yanhui Chu; yanhui_chu@sina.com and Bingbing Sun; bingbingsun@dlut.edu.cn

Received 15 May 2019; Revised 12 August 2019; Accepted 11 October 2019; Published 26 November 2019

Academic Editor: Yasuhiko Hayashi

Copyright (c) 2019 Haiyang Zhao et al. This is an open access article distributed under the Creative Commons Attribution License, which permits unrestricted use, distribution, and reproduction in any medium, provided the original work is properly cited.

\begin{abstract}
With the rapid development of nanotechnology, engineered nanomaterials (ENMs) have been applied in many fields, such as food industry, biomedicine, and so on. However, the study on the health and safety implications of ENMs is still insufficient. Previous studies have shown that nanoparticles under acute or chronic exposure could be transported and accumulated in various organs and tissues, resulting in adverse effects or systemic toxicity. Among these, the kidney is one of the main organs that exposed ENMs will target through different routes. One of the important functions of the kidney is to discharge metabolic wastes and exogenous substances from the blood circulation of the whole body. During ENM exposure, the kidney may become vulnerable to toxicity. Studies have suggested that nanoparticles exposed to the kidney could provoke glomerular swelling, basilar membrane thickening, degeneration, and necrosis of renal tubular cells. These adverse effects of nanoparticles on the kidney may be related to their induced oxidative stress, inflammation, autophagy, DNA damage, and ER stress. This review aims to examine current studies on ENM-induced nephrotoxicity, with the focus on elucidating the potential molecular mechanisms of nanoparticle-induced toxicity on the kidney, which will further facilitate the safer design of ENMs and their applications.
\end{abstract}

\section{Introduction}

In recent decades, engineered nanomaterials (ENMs) with novel physicochemical properties have been widely applied in various fields such as electronics, cosmetics, food additives, and biosensors $[1,2]$, and global ENM production is estimated to be more than 300,000 tons per year [3-5]. However, their safety is drawing more and more attention [6]. With ENM exposure, they could be accumulated and reside in the environment that could further lead to significant health issues [7]. The increasing use of ENMs has aroused people's worries regarding their undesirable side effects.

The ENMs can enter the lymph and blood carried in the blood stream through the epithelial and endothelial barrier, and with the flow of lymph to different organs and tissues [8]. It is noteworthy that ENMs can enter organs, tissues, and cells. In addition, it can also enter organelles, such as mitochondria and nucleus. ENMs can penetrate the cell membrane and damage the cell membrane through endocytosis and transmembrane [9]. ENMs could cause changes in membrane protein structure, disrupting the transport of substances into and out of cells, as well as intercellular transport [10]. ENMs could also damage the cytoskeleton of cells, interfering with cell transport and cell division. ENMs could damage Golgi apparatus and interferes with lysosome formation, thereby hindering autophagy and degrading large molecules and triggering apoptosis. When the mitochondria and the endoplasmic reticulum are damaged, cell energy imbalance and endoplasmic reticulum stress will be caused. Then, cells produce oxygen and other free radicals. Many studies have shown that oxidative stress plays a central role in ENMinduced toxicity [11-13]. Increased levels of ROS could lead 
to inflammation, DNA damage, cell cycle arrest, and ultimately apoptosis. All of these interfere with the normal mechanism of cell metabolism and metabolism of tissues and organs.

Because of its high blood supply and the ability to exclude harmful substances in the body, the kidneys are particularly susceptible to exogenous substances. The podocyte was the key participant of the glomerular filtration barrier; the cytotoxicity of ENMs will affect glomerular filtration function. The ENMs filtered by glomerular cells can further damage the kidney. After renal damage, the renal tubular epithelial cells can cause abnormal metabolism, biochemical disorders, structural and functional damage, producing oxygen free radicals, necrosis, or apoptosis. Necrotic renal tubular epithelial cells fall off from the basement membrane and release intracellular contents, causing local inflammatory cells to infiltrate, and can continue to act on renal tubular epithelial cells, which produces excessive extracellular matrix in the epithelial cells of the tubule and leads to the formation of renal interstitial fibrosis [14]. Studies have found that the apoptosis of renal tubular epithelial cells is one of the main causes of renal tubular dysfunction $[15,16]$.

Although current studies suggest that ENM exposure may potentially cause toxicities to the kidneys, we still need further studies to elucidate all the underlying molecular mechanisms regarding how these ENMs induce renal toxicity. The purpose of this review is to outline the nephrotoxicity of ENMs with different physicochemical properties and the related mechanisms.

\section{The Exposure Routes of ENMs and Their Distribution in the Kidney}

The ENMs can enter the body through various ways, e.g., inhalation, ingestion, skin uptake, injection, implantation, and direct penetration in cells and tissues (Figure 1) [17]. Among these, inhalation and injection are the most common ways of exposure. However, regardless of exposure route, ENMs can permeate into the bloodstream through different pathways and were spread through the blood circulation system to various organs [18]. The classic target organs include the kidney, heart, liver, spleen, lung, brain, and gastrointestinal tract $[19,20]$. During the metabolic process, the clearance of ENMs will undergo major pathways including hepatobiliary metabolism, urinary excretion, and fecal excretion [21, 22]. ENMs with sizes above $6 \mathrm{~nm}$ are mainly removed by the reticuloendothelial system (RES), e.g., liver and spleen. ENMs less than $6 \mathrm{~nm}$ can be efficiently filtered by the glomerulus and cleared from the body through the urinary system $[23,24]$. Excretion through the urinary system is considered a preferred choice for the removal of ENMs; it is faster and more effective in clearing ENMs than other pathways [25].

The kidney, a key organ of producing urine, plays an important role on removing the metabolites of the body and some waste and poison and retaining water and other useful substances, e.g., glucose, ions, and nutrients, by reabsorption function [26]. The kidney is also the last barrier for ENMs excreted from the body through the urinary system [27]. The glomerulus can filter ENMs in the blood through the glomerular filtration barrier (Figure 2). The glomerular filtration barrier is composed of glomerular endothelial cells, a glomerular basement membrane, and a podocyte [28]. The endothelial layer features $70-90 \mathrm{~nm}$ fenestrations and provides initial physical filtration barriers [24]. The glomerular endothelial cells are covered with functional glycocalyx $[23,29]$. The glomerular basement membrane (GBM) is a highly organized nonamorphous meshwork. The pore size of the podocyte layer is $4 \sim 11 \mathrm{~nm}$ and is covered by a layer of glycocalyx $[28,30]$. In healthy states, ENMs with a particle size less than $6 \mathrm{~nm}$ can be efficiently filtered by the glomerulus and then excreted with urine $[23,24]$. In the condition of a disease, the loss of podocytes leads to the breakdown of the glomerular filtration barrier. Leakage and abnormal fenestrae will contribute to the accumulation of larger ENMs in the Bowman space [28]. Renal tubular epithelial cells have a strong reabsorption function, and therefore become the main accumulation sites of glomerular-filtrated ENMs [22, 31]. Excessive accumulation of ENMs in glomerular and tubular cells can lead to kidney damage and affect the normal function of the kidney, mainly in the form of oxidative stress, inflammation, DNA damage, autophagy, and endoplasmic reticulum stress [12, 32].

\section{Molecular Mechanism of Renal Toxicity Induced by ENMs}

3.1. Oxidative Stress Induced by ENMs. Reactive oxygen species (ROS) are chemically reactive species [33] including hydroxyl $\left({ }^{\circ} \mathrm{OH}\right)$, superoxide $\left(\mathrm{O}_{2}{ }^{-}\right)$, hypochlorous acid $(\mathrm{HOCl})$, singlet oxygen $\left({ }^{1} \mathrm{O}_{2}\right)$, and ozone $\left(\mathrm{O}_{3}\right)$ [34]. ROS are bioproducts of oxygen metabolism in various cell compartments, including the cell membrane, cytoplasm, mitochondria, and endoplasmic reticulum (ER). Mitochondria are major sources of ROS production [35].

Oxidative stress is considered to be one of the most important mechanisms of ENM-induced nephrotoxicity (Figure 3) [9, 36, 37]. Oxidative stress is characterized by an increase in ROS, which is essentially an imbalance between ROS production and antioxidant defense [38]. Under normal conditions, only a small amount of active oxygen is produced in the body. In the kidney, the main role of ROS and their derivative molecules regulates the resorption of solutes and water, which is essential for maintaining electrolyte homeostasis and extracellular fluid volume [39]. Studies have demonstrated that various types of ENMs, e.g., gold, silver, and copper, were able to induce intracellular ROS production. However, the link between ENMs and oxidative stress markers has not been well established. ENMs can pass through the cell membrane through active transport or passive diffusion [9]. The uptake of ENMs by glomerular and tubular cells plays a central role in direct or indirect ROS production, which is related to the size, chemical composition, and surface reactivity of ENMs [13, 40-42]. The smaller the particles, the more surface masses per unit mass and the stronger their reactivity during ENM-cell interaction. The surface area of ENMs was highly correlated with their ability to generate ROS $[9,43]$. Animal studies showed that 10,20 , and $50 \mathrm{~nm}$ gold nanoparticles (GNPs) could destroy the function of the kidneys. Histological changes were mainly seen in the cortex, and more toxicity was induced in proximal 


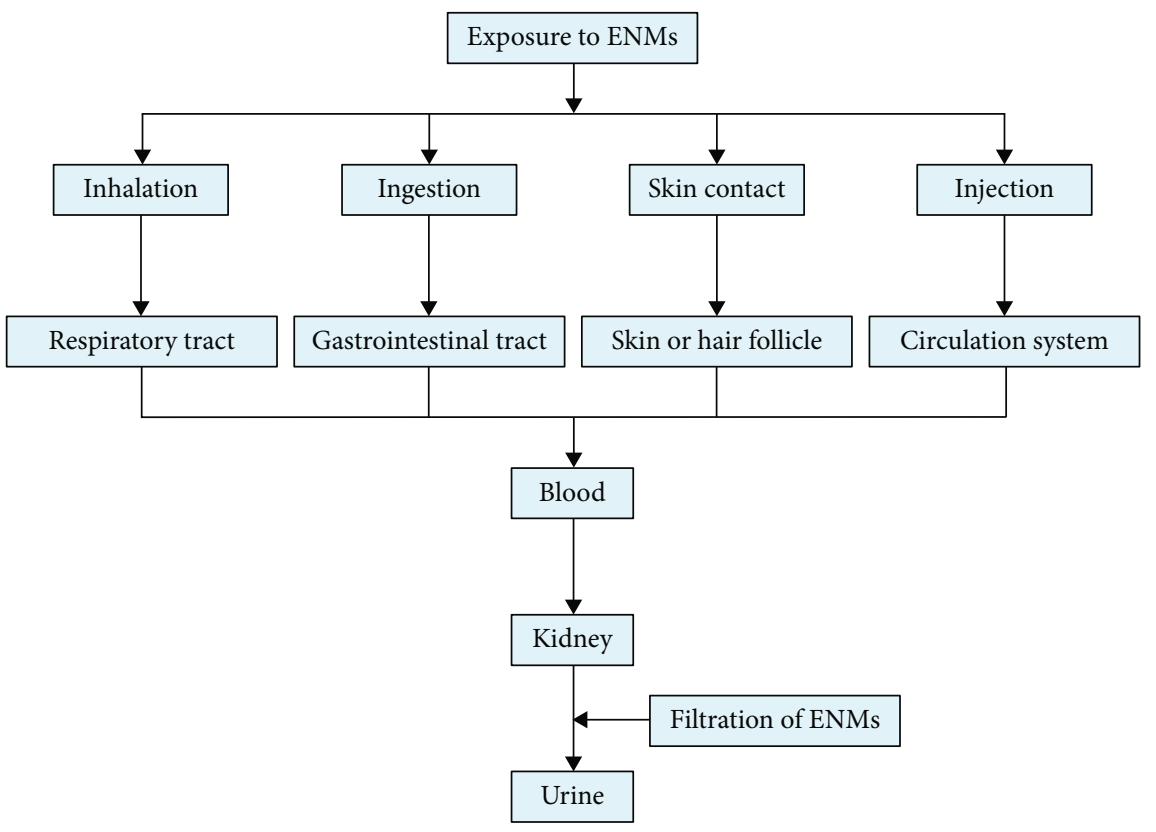

FiguRE 1: The exposure routes and transport of ENMs in the human body.

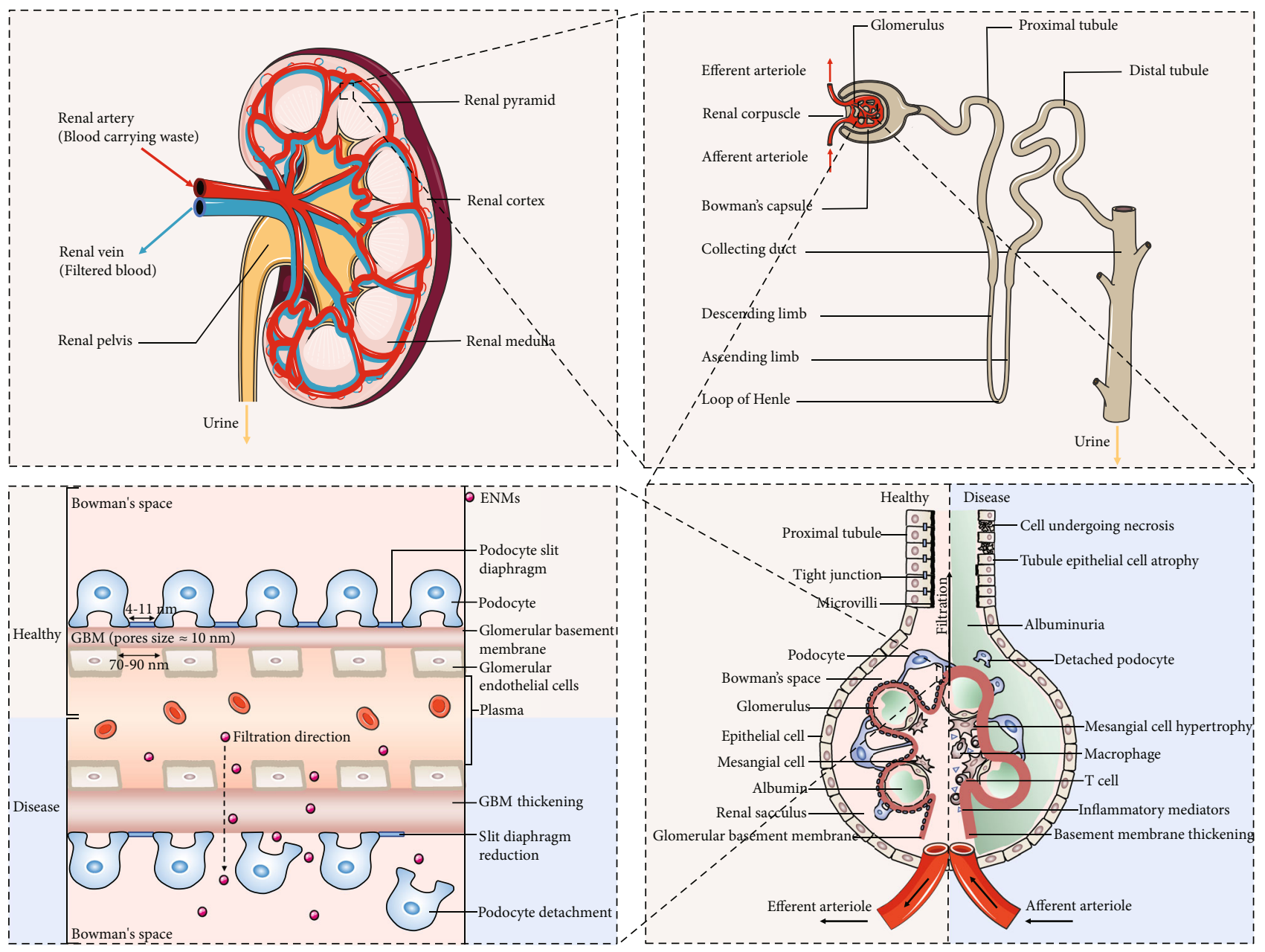

FIGURE 2: Transport of ENMs in the kidneys and damage to the kidneys. 


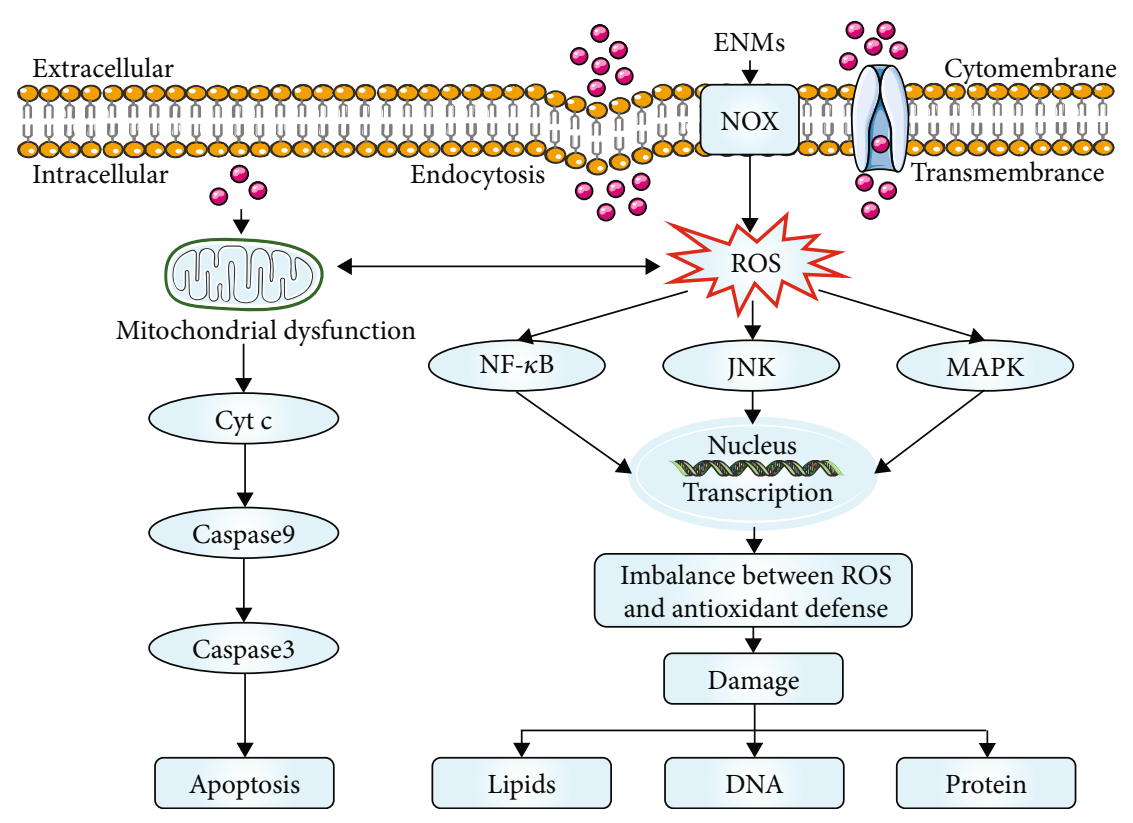

Figure 3: Mechanism of renal oxidative stress induced by ENMs.

tubules than distal renal tubules. The damage caused by smaller GNPs $(10 \mathrm{~nm})$ is more serious. Exposure to GNPs has produced changes in renal tubules and caused atrophy and necrosis of renal cells. These may be due to the interaction of GNPs with enzymes and proteins in the kidney, interfering with antioxidant defense mechanisms, leading to the production of ROS. The degree of renal injury is related to the exposure time of GNPs [44]. In two renal proximal tubular cell lines (human HK-2 and porcine LLC-PK1), the induced toxicity is time-dependent. Cytotoxicity also increases with the decrease of nanoparticle size. $20 \mathrm{~nm}$ Si NPs led to more oxidative stress [37]. Accumulated ENMs in the kidney can cause a dramatic increase in ROS levels, as well as a decrease in protective molecules and enzymes, loss of mitochondrial membrane potential, and subsequent ROS-mediated damage to various cellular components, including lipids, DNA, and proteins, which could lead to the destruction of cellular structural integrity and eventual apoptosis [42]. At the molecular level, it was found that CuSNPs could lead to reactive oxygen species (ROS) generation, subsequent PARP lysis, and cell death in HEK293 cells [45]. In HK2 and HEK293 cell lines, silver nanoparticles were found to increase the production of reactive oxygen species and reduce cell viability [46]. Meanwhile, Nrf2-mediated GSH increase plays a protective role in Ag NP-induced toxicity [47]. A large number of studies have shown that oxidative stress also plays an important role for podocyte injury $[48,49]$. ROS overproduction can cause podocyte injury, including DNA damage and apoptosis $[50,51]$. In vitro studies showed that copper NPs affected the oxidant-antioxidant balance, resulting in increased production of ROS and malondialdehyde (MDA), decreased podocyte activity, and significantly increased apoptosis $[49,52]$. MDA, as an indicator of the extent of lipid peroxidation, is generally considered an indicator of cell damage $[49,53]$. Collectively, ENM-induced oxidative stress can lead to metabolic disorders and inflammation signal transduction, thereby affecting the normal function of the kidney.

3.2. Inflammation Induced by ENMs. Inflammation is the response of the immune system to stimuli, such as damaged cells, pathogens, toxic compounds, or radiation [54]. It plays an important role in removing harmful stimuli and initiating the healing process [55]. Inflammation is a crucial defense mechanism for health. Coordinate activation of multiple signaling pathways is one of the characteristics of the inflammatory response, which regulates the expression of the anti-inflammatory mediators in the tissue cells and leukocytes recruited from the blood [56].

ENMs can be recognized by immune cells, which further produce inflammatory responses, including secreting signaling molecules or cytokines to attract more cells to destroy foreign bodies (Figure 4) [57, 58]. Microbiological products and cytokines, such as interleukin- $1 \beta$ (IL-1 $\beta$ ), interleukin-6 (IL-6), and tumor necrosis factor-alpha (TNF- $\alpha$ ), can stimulate intracellular signaling pathways and then lead to inflammation [59]. Studies have shown that increased expression of IL- $1 \beta$, IL-6, TNF- $\alpha$, and other proinflammatory cytokines can lead to impairment of renal function and structure [6062]. Previous studies have demonstrated that a variety of ENMs, including mesoporous silica nanoparticles (MSNs) and Ag NPs, could cause nephrotoxicity that was mediated by inflammation. On the one hand, these ENMs can activate multiple typical proinflammatory signaling pathways such as $\mathrm{NF}-\kappa \mathrm{B}$ signaling pathway, which regulates the production of inflammatory cytokines and the recruitment of inflammatory cells. It plays an important role in inflammation, immune response, cell survival, and apoptosis [63]. In vitro studies showed that MSNs induced cytotoxicity in NRK-52E cells and increased the expression of fibrotic markers, such as TGF- $\beta$, fibronectin, and ICAM-1. In animal experiments, the expression of NF- $\kappa \mathrm{B}$ p 65 and the nuclear translocation 


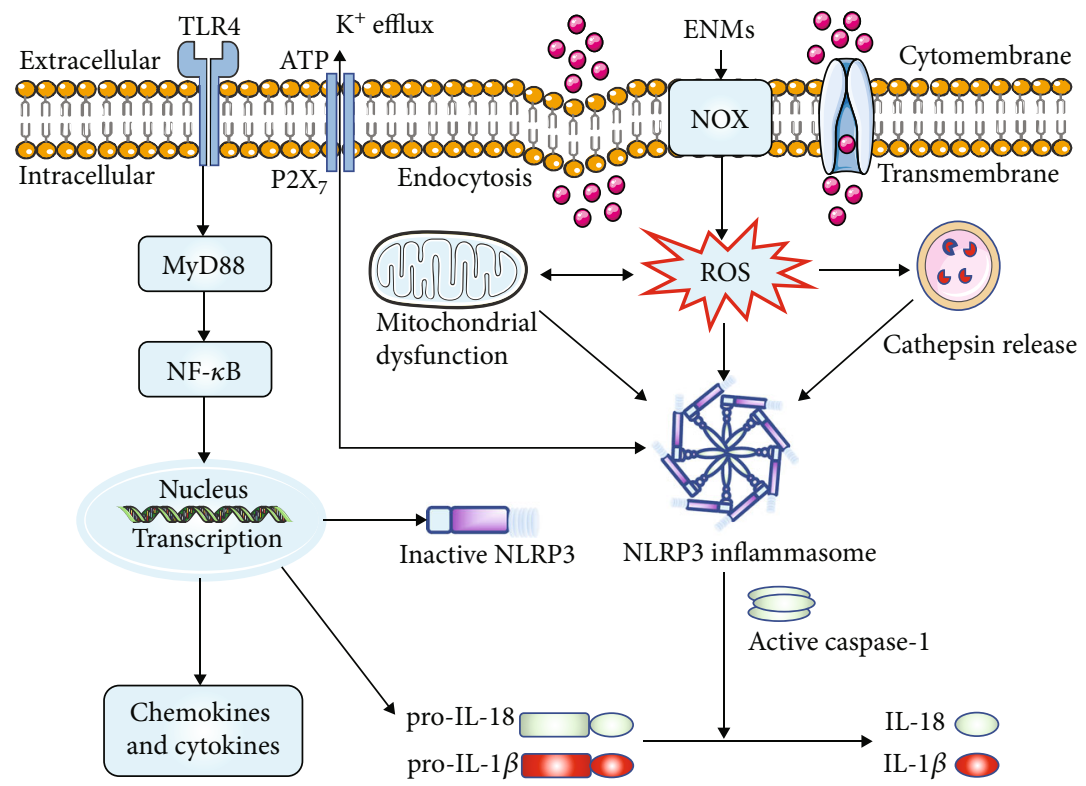

FIgURE 4: Mechanism of renal inflammation induced by ENMs.

increased in the renal tissue after exposure to MSNs. This indicates that inflammation is the main effect of MSNinduced acute nephrotoxicity [14]. Studies have demonstrated that long-term exposure to Ag NPs can promote renal ultrastructural damage and induce mitochondrial rupture and inflammation in rats, which is closely related to the activation of the Akt/mTOR, JNK/Stat, and Erk/NF- $\kappa$ B pathways [64]. On the other hand, excessive accumulation of ENMs in the kidney can also cause inflammation. A study has shown that ingestion of Ag NPs could cause their accumulation in animal kidneys. These Ag NPs could cause inflammation and cell damage by forming complexes with proteins or other cellular biomolecules in the kidneys. At the same time, Ag NPs can lead to hypertrophy and fusion of the proximal tubule endothelial cells and thickening of the podocyte and basement membrane [65]. Inflammation and inflammatory reactions are not only the main causes of kidney damage and nephron loss but also the cause of the progression of chronic kidney disease (CKD) [66]. Collectively, a series of synergistic mechanisms of ENM-induced inflammation are involved in tissue damage, extracellular matrix remodeling, oxidative stress, and fibrosis in kidney.

3.3. Autophagy Induced by ENMs. Autophagy is an important process to maintain normal function and structure of cells in all eukaryotes [67]. It can degrade and recycle damaged organelles and macromolecules through the lysosomal pathway $[68,69]$. Autophagy is mainly involved in the degradation of long-lived proteins, while ephemeral proteins can be degraded by the ubiquitin proteasome pathway [70, 71].

The kidney, as the excretory organ of mammals, is composed of many kinds of cells. Under physiological conditions, these cells have a high level of autophagy to complete their filtration function [72]. However, many cytotoxic stimuli can induce autophagy, including many types of ENMs, e.g., gold, iron, zinc, titanium, and bismuth. Moreover, many
ENMs are selective nephrotoxic substances that preferentially accumulate in the kidneys, which can lead to further kidney damage (Figure 5) [41, 73]. Under certain stress conditions, the autophagy of the kidneys is activated [74]. There is evidence showing that bismuth NPs (BiNPs) can induce the occurrence of autophagy and increase the expression of LC3II in the HEK293 cell line. BiNP-induced renal cytotoxicity may be due to the release of bismuth ions in NPs [75] Further animal experiments showed that ROS produced by BiNPs may be the main inducement of autophagy, and ROS blockade can reduce autophagy. Autophagy induced by BiNPs is mainly regulated by the AMPK/mTOR signaling pathway [76]. Under normal conditions, GNPs can be deposited in the kidneys, particularly in renal tubular epithelial cells $[44,77]$. In the HK2 cell line, $5 \mathrm{~nm}$ GNP (50 nM) treatment could cause autophagy and cell survival. Electron microscopy revealed that $5 \mathrm{~nm}$ GNPs were mainly localized in vesicles or lysosomes; it is the direct evidence for the formation of autophagy [78]. Chronic hypoxic is inevitable in chronic kidney diseases; in hypoxic conditions, the same dose of $5 \mathrm{~nm}$ GNP $(50 \mathrm{nM})$ exposure resulted in the production of reactive oxygen species, loss of mitochondrial membrane potential, and increased apoptosis and autophagic cell death in the HK2 cell line. It may be due to GNP-induced ROS triggering autophagy directly or indirectly by inhibiting classical autophagy (PI3K/Akt/mTOR) signaling pathways [78]. This suggests that the potential GNP-related treatment for patients with chronic kidney disease is at risk. Another study shows that oral intake of ZnO NPs in mice will lead to glomeruli segmentation, hydropic degeneration in epithelial cells, necrosis of epithelial cells in tubules, and swelling in epithelial cells of proximal tubules [79]. Hypoxia-inducible factor-1 (HIF-1) is a transcription factor that mediates adaptive responses to hypoxia at cellular and systemic levels [80]. The experiments have also proved that $\mathrm{ZnO} \mathrm{NP}$ nephrotoxicity can be associated with ROS-induced HIF-1 alpha 


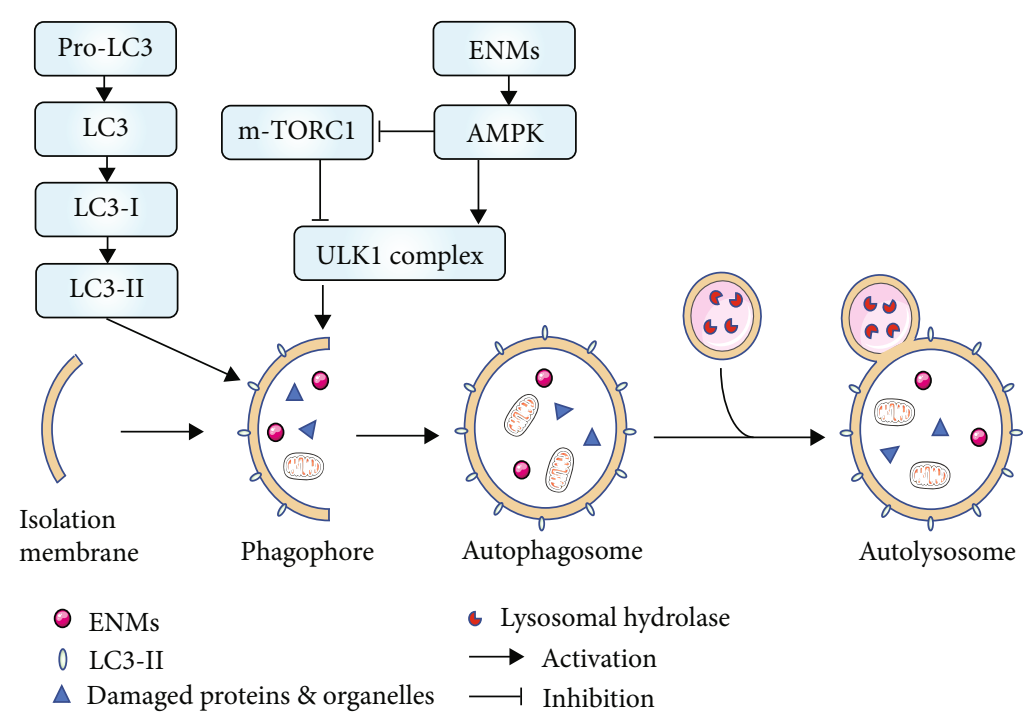

FIgURE 5: Mechanism of renal autophagy induced by ENMs.

signaling pathway, apoptosis, and autophagy. HIF-1 knockout can result in a significant decrease in autophagy level, but increase in cytotoxicity. It is suggested that HIF-1 alpha may have protective effects on $\mathrm{ZnO} \mathrm{NP}$-induced nephrotoxicity [79]. In addition to tubular cells, ingestion of ENMs can also trigger autophagy of glomerular podocytes. Podocytes play an important role in glomerular filtration. Changes in podocyte autophagy are critical to the survival of cells under physiological or stress conditions [72]. Research shows that the glomeruli podocyte has a high rate of autophagy to maintain a terminally differentiated cell [81]. In a mouse podocyte cell line, $\mathrm{TiO}_{2}$ NPs induce autophagy by activating AMPK, which inhibits mTOR, and this autophagy as an antioxidant system protect podocytes from death [72]. Research shows that $\mathrm{Fe}_{3} \mathrm{O}_{4}$ NPs can damage the lysosomes and lead to the accumulation of LC3-positive autophagosomes and can also cause mitochondrial damage and ER stress, resulting in the accumulation of autophagosomes in the kidneys of mice [82]. However, PLGA-coated $\mathrm{Fe}_{3} \mathrm{O}_{4}$ NPs reduce damage effect in the kidney. Because PLGA-coated $\mathrm{Fe}_{3} \mathrm{O}_{4}$ NPs enter cells through the endocytosis pathway and then transported to the lysosome for degradation, the lysosome can directly transport the remaining residues from cells, thus reducing the chance of NP contact with organelles in the cytoplasm and the cytotoxicity induced by NPs [82]. These studies indicate that although autophagy is a cytoprotective mechanism for ENM-induced nephrotoxicity, excessive self-degradation may also damage renal cells.

3.4. DNA Damage Induced by ENMs. The exposure of ENMs could lead to potential DNA damage [83]. The main form of DNA damage includes base loss and base pair mismatch DNA single-strand breaks (SSB) and double-strand breaks (DSBS) [84]. DNA damage activates specific cascades of cellular signals, which then act on DNA repair, cell cycle arrest, senescence, or cell death [85]. The complex mechanisms of DNA damage and repair jointly determine the fate of the affected cells (Figure 6).
Numerous studies have shown that a variety of ENMs can cause DNA damage in the kidney. ROS is considered to be a genotoxic mechanism of ENMs, which can promote oxidative DNA damage [86]. Several in vitro studies have shown that Ag NPs may trigger ROS production by mediating mitochondrial dysfunction, leading to DNA damage $[87,88]$. In the HK2 cell line, Ag NPs can induce ROS-mediated DNA damage and subsequent G2/M cell cycle arrest in human renal epithelial cells. The DNA damage signal induced by Ag NPs was first transduced by ataxia telangiectasia mutated (ATM) and Ataxia- and Rad-related (ATR) kinases. Furthermore, G2/M checkpoints can be activated by the inhibition of cell division cyclin 25 homolog $\mathrm{C}$ (CDC25C) and the activation of p53 signaling [47]. p53 is a key participant in the intrinsic cellular response of DNA damage. Activation of p53 leads to cell cycle arrest, apoptosis, and aging [89]. Cells with severe DNA damage will cease to grow and cause apoptosis. Transcription factor NF-E2-related factor 2 (NRF2) controls the expression of various antioxidant genes. Knockout of Nrf2 can enhance the cytotoxicity of Ag NPs [47]. In addition to $\mathrm{Ag}$ NPs, $\mathrm{CuO}$ NPs and $\mathrm{TiO}_{2}$ NPs could also produce ROS and cause DNA damage, and eventually lead to cell death through apoptosis $[40,90,91]$. The degree of oxidative stress is closely related to the dose and time of injection [92]. In HEK293 cell line, exposure to 20 or $50 \mathrm{~nm}$ Si NPs resulted in a dose-dependent reduction in cell viability. Flow cytometry analysis showed that Si NPs could cause G2/M arrest, and exposure to Si NPs resulted in increased cytotoxicity and oxidative stress [93]. Studies have shown that blocking cell cycle progression at $\mathrm{G} 2 / \mathrm{M}$ checkpoints can enhance apoptosis through the JNK-dependent pathway that lead to renal fibrosis [94-96]. In rat kidney epithelial cells (NRK-52E), 12.5-50.0 $\mu \mathrm{g} / \mathrm{mL} \mathrm{ZnO}$ NPs induced genotoxicity and caused statistically significant DNA damage. The interaction between $\mathrm{ZnO}$ NPs and cells can increase the production of reactive oxygen species (ROS), resulting in DNA strand breakage, oxidative DNA adducts, DNA crosslinking, and DNA-protein crosslinking. When $\mathrm{ZnO} \mathrm{NPs}$ dissolve, zinc ions will be 


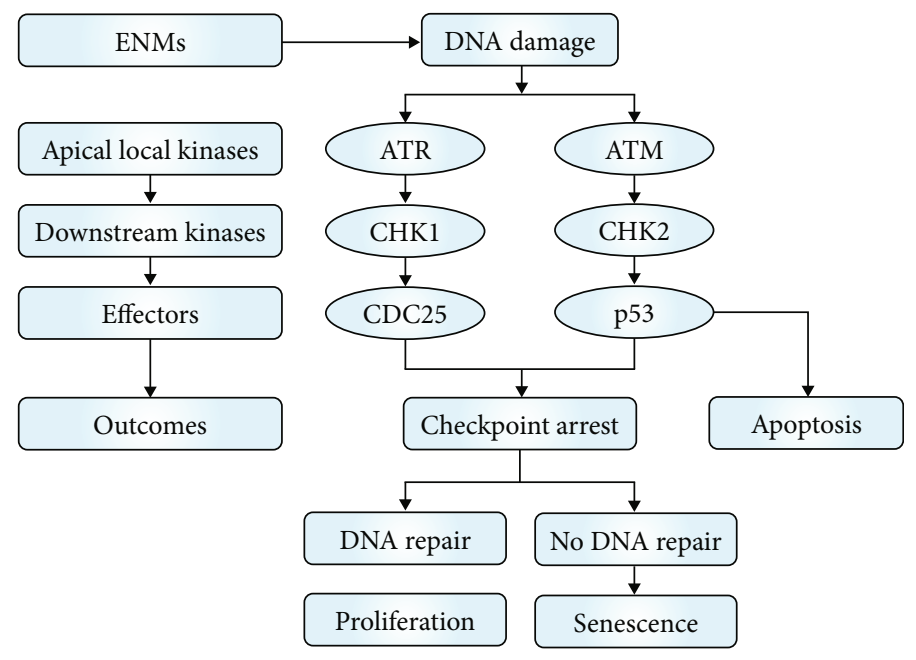

FIgure 6: Mechanism of renal DNA damage induced by ENMs.

released, which can destroy zinc homeostasis in cells, cause lysosome and mitochondria damage, and ultimately lead to cell death [97]. DNA damage induced by ENMs is also closely related to its physical and chemical properties. There is evidence to show that in human proximal tubule cells (HPTC), a high dose of $40 \mathrm{~nm}$ branched polyethylenimine (BPEI) AuNPs can regulate DNA damage and repair pathway, apoptosis, and heat shock response. Compared with lipoic acid(LA-) and polyethylene glycol- (PEG-) coated AuNPs, the smaller $40 \mathrm{~nm}$ BPEI AuNPs tend to have greater cell uptake and cytotoxicity once it enters the renal tubular cells, suggesting that nephrotoxicity is more likely to happen [98]. The regulation of DNA damage is important for maintaining the normal function of the renal system. A large number of human kidney diseases are closely related to the defects of DNA damage response [99-103]. Therefore, more attention should be paid to ENM-induced DNA damage.

3.5. Endoplasmic Reticulum Stress Induced by ENMs. The endoplasmic reticulum (ER) is an organelle for protein synthesis, folding, assembly, and modification [104]. ER stress is caused by accumulation of unfolded proteins in the endoplasmic reticulum [105]. ER stress, also known as the unfolded protein response (UPR), can affect a series of cell feedback loops and strictly control the function of the ER [104]. The main regulator of the UPR signal network is the ER chaperone protein, glucose-regulated protein 78 (GRP78). Under the condition of ER stress, GRP78 first combines unfolded or misfolded proteins and separates them from 3 major ER sensors, including inositol requiring- $1 \alpha$ (IRE1 $\alpha$ ), protein kinase R-like ER kinase (PERK), and activating transcription factor 6 (ATF6) (Figure 7) [106].

ER stress occurs frequently in a variety of pathophysiological conditions, such as neurodegenerative disorders, diabetes mellitus, ischemic injury, inflammation, infection, and toxicity of chemicals and metals [107-109]. ER stress and misfolding of protein also exists in many kidney diseases, including acute renal injury, chronic renal disease, glomerular disease associated with genetic mutations, primary glomerulonephritis, renal fibrosis, and diabetic nephropathy.
Previous studies have shown that in specific kidney diseases, renal damage can be reduced by improving protein folding [110]. Currently, there are relatively few reports of renal ER stress induced by ENMs; however, due to the wide application prospects of ENMs, we still need to pay attention to its potential toxicity. There is evidence to show that $\mathrm{Fe}_{3} \mathrm{O}_{4}$ and PLGA-coated $\mathrm{Fe}_{3} \mathrm{O}_{4}$ NPs can be absorbed by cells through endocytosis. $\mathrm{Fe}_{3} \mathrm{O}_{4}$ NPs could destroy the lysosome and cause mitochondrial damage, ROS, and ER stress, resulting in the accumulation of autophagy in the kidney of mice, thereby affecting the normal function of the kidneys [82]. Disturbance of oxidative stress and hypoxia could lead to ER dysfunction, further induce ER stress and subsequent unfolded protein response (UPR). UPR is an adaptive response; it induces apoptosis in severe or long-term ER stress [111]. Studies have also shown that ER stress is a major factor leading to the apoptosis of renal tubular epithelial cells [112]. In vivo experiments showed that different tissues had different sensitivity to Ag NPs after intratracheal drip exposure in mice. Quantitative analysis of ER marker genes including chop, $x b p-1 s$, and $\mathrm{BiP}$ showed that the mice exposed to $2 \mathrm{mg}$ of Ag NPs had obvious endoplasmic reticulum stress response in the kidney, lung, and liver. However, TUNEL assay showed only apoptosis in the lung and kidney [113]. ER stress is an important mechanism of cell selfprotection. It can be used as an early biomarker to evaluate the toxicity of exogenous stimulants [113].

\section{Conclusion and Perspectives}

The present review provided an overview on ENM-induced nephrotoxicity and its potential mechanisms. Current studies suggest that the toxicity of ENMs in the kidney depends largely on their physical and chemical properties, such as the size, shape, electric charge, and chemical compositions. Particle size is the main factor that makes ENMs more toxic than normal particles. Reducing particle size will increase the surface area of particles. The small size effect and large specific surface area of ENMs can interact with cell membranes, thereby destroying the integrity of cell membranes. At the 


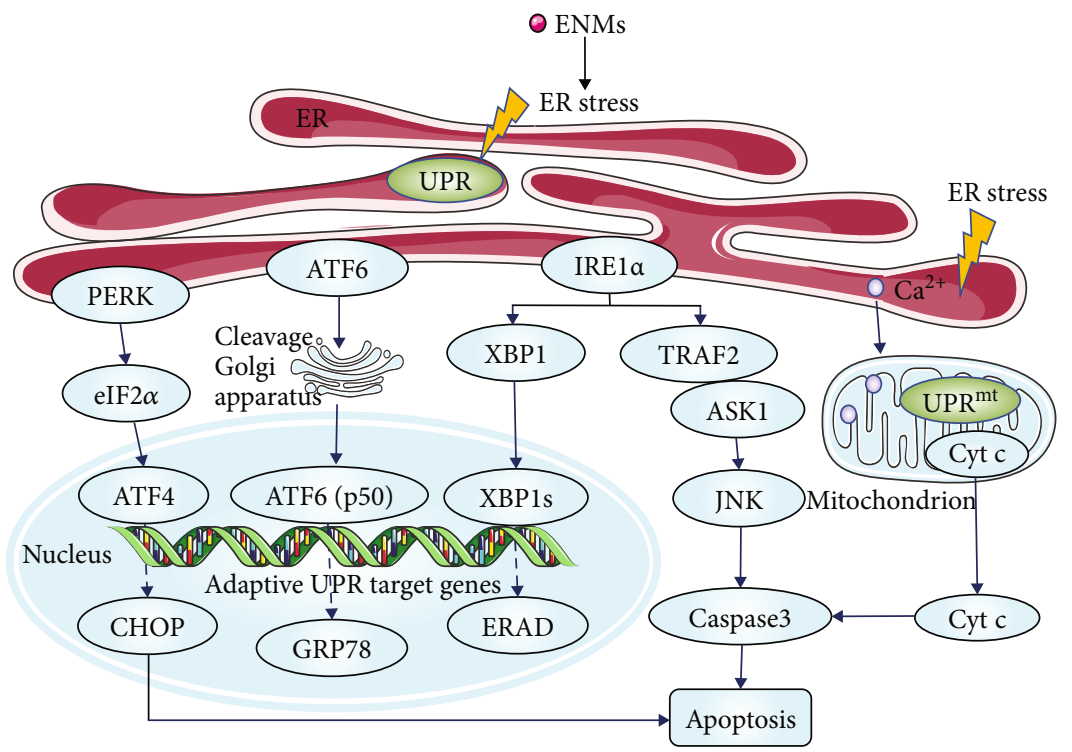

Figure 7: Mechanism of renal endoplasmic reticulum stress induced by ENMs.

same time, it enters the organelles such as mitochondria and nuclei and reacts with intracellular mitochondria, lysosomes, and other substances. The decomposed ENMs may further generate a large number of free radicals, which may cause the damage of the cell's ultrastructure and function [114-116]. Numerous in vivo studies have shown that the smaller the size of nanoparticles, the higher the degree of damage, the more toxic the kidney appears [44, 77, 117]. The ENMinduced nephrotoxicity is not only affected by size factors but also closely related to the shape of ENMs. Animal experiments show that the degradation products released by different shapes of ENMs during biodegradation are also different. If the size of degradation products is larger than the renal filtration threshold of about 10 nanometers, it can be slowly cleared through renal filtration, thus causing damage to the glomerular structure. If they are degraded into small molecules of 10 nanometers smaller than the renal filtration threshold, they may undergo glomerular filtration; however, they will be absorbed by the renal tubules and cause damage to the renal tubules [118]. Additionally, studies show that the surface charge of particles played an important role in nephrotoxicity, and the cytotoxicity of positive-charged nanoparticles is stronger than that of negative-charged nanoparticles. This may be related to the negative charge on the cell membrane. When cationic nanoparticles destroy the cell membrane, they mainly punch holes in the cell membrane. The membranes become thinner or corrode, causing damage to kidney cells [119]. Functional groups could be grafted to ENMs that could alter cytotoxicity [120]. In vivo experiments showed that PLGA-coated $\mathrm{Fe}_{3} \mathrm{O}_{4}$ nanoparticles could enter cells through endocytosis and then be transported to lysosomes for degradation, which reduced the chance of contact with organelles. Compared with unmodified $\mathrm{Fe}_{3} \mathrm{O}_{4}$ nanoparticles, PLGA-coated $\mathrm{Fe}_{3} \mathrm{O}_{4}$ nanoparticles could reduce renal damage [82]. When these ENMs of different properties are transported to the kidney, they can further induce the apoptosis and necrosis of kidney cells by inducing oxidative stress, inflammation, autophagy, DNA damage, and ER stress and ultimately lead to the destruction of kidney function. However, these mechanisms do not exist independently. Oxidative stress plays a central role in ENM-induced nephrotoxicity. Increased levels of reactive oxygen species can cause abnormal metabolism, biochemical disorders, and structural and functional damage of renal cells and further trigger the occurrence and development of other toxicities. Therefore, the specific mechanism of this ENM-induced nephrotoxicity and its intricate interaction are still not fully elucidated. At present, most of the studies on ENM-induced nephrotoxicity are based on animal and cell tests, and different experimental models can affect the toxicity of ENMs. Moreover, the ENMinduced nephrotoxicity is mainly focused on the analysis of its biological distribution, cell damage, organ system damage, and other pathological aspects, but less on the mechanisms. It is necessary for us to explore the potential mechanism of ENM-induced nephrotoxicity more deeply and establish an effective method system for evaluating ENM-induced nephrotoxicity, which will help us avoid the potential risks of ENM-induced nephrotoxicity for safer and effective applications of ENMs in the future.

\section{Conflicts of Interest}

The authors declare that there is no conflict of interest regarding the publication of this paper.

\section{Authors' Contributions}

Haiyang Zhao and Luxin Li contributed equally to this work.

\section{References}

[1] A. Karmakar, Q. Zhang, and Y. Zhang, "Neurotoxicity of nanoscale materials," Journal of Food and Drug Analysis, vol. 22, no. 1, pp. 147-160, 2014. 
[2] J. L. West and N. J. Halas, "Engineered nanomaterials for biophotonics applications: improving sensing, imaging, and therapeutics," Annual Review of Biomedical Engineering, vol. 5, pp. 285-292, 2003.

[3] L. Goswami, K. H. Kim, A. Deep et al., "Engineered nano particles: nature, behavior, and effect on the environment," Journal of Environmental Management, vol. 196, pp. 297-315, 2017.

[4] M. S. Mauter, I. Zucker, F. Perreault, J. R. Werber, J. H. Kim, and M. Elimelech, "The role of nanotechnology in tackling global water challenges," Nature Sustainability, vol. 1, no. 4, article 46, pp. 166-175, 2018.

[5] A. A. Keller, S. McFerran, A. Lazareva, and S. Suh, "Global life cycle releases of engineered nanomaterials," Journal of Nanoparticle Research, vol. 15, no. 6, p. 1692, 2013.

[6] V. Mirshafiee, W. Jiang, B. Sun, X. Wang, and T. Xia, "Facilitating translational nanomedicine via predictive safety assessment," Molecular Therapy, vol. 25, no. 7, pp. 1522-1530, 2017.

[7] J. D. Judy and P. Bertsch, "Engineered nanomaterials in the environment," Nanomaterials, vol. 6, no. 6, p. 106, 2016.

[8] A. Sarkar, M. Ghosh, and P. C. Sil, "Nanotoxicity: oxidative stress mediated toxicity of metal and metal oxide nanoparticles," Journal of Nanoscience and Nanotechnology, vol. 14, no. 1, pp. 730-743, 2014.

[9] P. Møller, N. R. Jacobsen, J. K. Folkmann et al., "Role of oxidative damage in toxicity of particulates," Free Radical Research, vol. 44, no. 1, pp. 1-46, 2010.

[10] S. Barua and S. Mitragotri, "Challenges associated with penetration of nanoparticles across cell and tissue barriers: a review of current status and future prospects," Nano Today, vol. 9, no. 2, pp. 223-243, 2014.

[11] U. A. Reddy, P. V. Prabhakar, and M. Mahboob, "Biomarkers of oxidative stress for in vivo assessment of toxicological effects of iron oxide nanoparticles," Saudi Journal of Biological Sciences, vol. 24, no. 6, pp. 1172-1180, 2017.

[12] A. Nemmar, P. Yuvaraju, S. Beegam, J. Yasin, E. E. Kazzam, and B. H. Ali, "Oxidative stress, inflammation, and DNA damage in multiple organs of mice acutely exposed to amorphous silica nanoparticles," International Journal of Nanomedicine, vol. 11, pp. 919-928, 2016.

[13] L. Xiao, C. Liu, X. Chen, and Z. Yang, "Zinc oxide nanoparticles induce renal toxicity through reactive oxygen species," Food and Chemical Toxicology, vol. 90, pp. 76-83, 2016.

[14] X. Chen, W. Zhouhua, Z. Jie et al., "Renal interstitial fibrosis induced by high-dose mesoporous silica nanoparticles via the NF- $\kappa$ B signaling pathway," International Journal of Nanomedicine, vol. 10, pp. 1-22, 2015.

[15] D. P. Basile, M. D. Anderson, and T. A. Sutton, "Pathophysiology of acute kidney injury," Comprehensive Physiology, vol. 2, no. 2, pp. 1303-1353, 2012.

[16] K. Berger and M. J. Moeller, "Mechanisms of epithelial repair and regeneration after acute kidney injury," Seminars in Nephrology, vol. 34, no. 4, pp. 394-403, 2014.

[17] C. Gonzalez, H. Rosas-Hernandez, M. A. Ramirez-Lee, S. Salazar-García, and S. F. Ali, "Role of silver nanoparticles (AgNPs) on the cardiovascular system," Archives of Toxicology, vol. 90, no. 3, pp. 493-511, 2016.

[18] D. Docter, D. Westmeier, M. Markiewicz, S. Stolte, S. K. Knauer, and R. H. Stauber, "The nanoparticle biomolecule corona: lessons learned-challenge accepted?," Chemical Society Reviews, vol. 44, no. 17, pp. 6094-6121, 2015.
[19] S. Lanone and J. Boczkowski, "Biomedical applications and potential health risks of nanomaterials: molecular mechanisms," Current Molecular Medicine, vol. 6, no. 6, pp. 651663, 2006

[20] G. Oberdörster, A. Maynard, K. Donaldson et al., "Principles for characterizing the potential human health effects from exposure to nanomaterials: elements of a screening strategy," Particle and Fibre Toxicology, vol. 2, no. 1, article 1743-89772-8, p. 8, 2005.

[21] F. Chen, S. Goel, R. Hernandez et al., "Dynamic positron emission tomography imaging of renal clearable gold nanoparticles," Small, vol. 12, no. 20, pp. 2775-2782, 2016.

[22] M. Yu and J. Zheng, "Clearance pathways and tumor targeting of imaging nanoparticles," ACS Nano, vol. 9, no. 7, pp. 6655-6674, 2015.

[23] J. Wang and G. Liu, "Imaging nano-bio interactions in the kidney: toward a better understanding of nanoparticle clearance," Angewandte Chemie, vol. 57, no. 12, pp. 3008-3010, 2018.

[24] B. Du, X. Jiang, A. Das et al., "Glomerular barrier behaves as an atomically precise bandpass filter in a sub- nanometre regime," Nature Nanotechnology, vol. 12, no. 11, article BFnnano2017170, pp. 1096-1102, 2017.

[25] M. Longmire, P. L. Choyke, and H. Kobayashi, "Clearance properties of nano-sized particles and molecules as imaging agents: considerations and caveats," Nanomedicine, vol. 3, no. 5, pp. 703-717, 2008.

[26] P. Bhargava and R. G. Schnellmann, "Mitochondrial energetics in the kidney," Nature Reviews Nephrology, vol. 13, no. 10, pp. 629-646, 2017.

[27] B. George, D. You, M. S. Joy, and L. M. Aleksunes, "Xenobiotic transporters and kidney injury," Advanced Drug Delivery Reviews, vol. 116, pp. 73-91, 2017.

[28] N. Kamaly, J. C. He, D. A. Ausiello, and O. C. Farokhzad, "Nanomedicines for renal disease: current status and future applications," Nature Reviews Nephrology, vol. 12, no. 12, pp. 738-753, 2016.

[29] A. L. Rops, M. A. Loeven, J. van Gemst et al., "Modulation of heparan sulfate in the glomerular endothelial glycocalyx decreases leukocyte influx during experimental glomerulonephritis," Kidney International, vol. 86, no. 5, pp. 932-942, 2014.

[30] B. Du, M. Yu, and J. Zheng, "Transport and interactions of nanoparticles in the kidneys," Nature Reviews Materials, vol. 3, no. 10, pp. 358-374, 2018.

[31] H. S. Choi, W. Liu, P. Misra et al., "Renal clearance of quantum dots," Nature Biotechnology, vol. 25, no. 10, pp. 11651170, 2007.

[32] M. Milić, G. Leitinger, I. Pavičić et al., "Cellular uptake and toxicity effects of silver nanoparticles in mammalian kidney cells," Journal of Applied Toxicology, vol. 35, no. 6, pp. 581592, 2015.

[33] M. Hayyan, M. A. Hashim, and I. M. AlNashef, "Superoxide ion: generation and chemical implications," Chemical Reviews, vol. 116, no. 5, pp. 3029-3085, 2016.

[34] K. Bedard and K. H. Krause, "The NOX family of ROSgenerating NADPH oxidases: physiology and pathophysiology," Physiological Reviews, vol. 87, no. 1, pp. 245-313, 2007.

[35] Q. Chen, S. Moghaddas, C. L. Hoppel, and E. J. Lesnefsky, "Ischemic defects in the electron transport chain increase the production of reactive oxygen species from isolated rat 
heart mitochondria," American Journal of Physiology-Cell Physiology, vol. 294, no. 2, pp. C460-C466, 2008.

[36] F. Marano, S. Hussain, F. Rodrigues-Lima, A. Baeza-Squiban, and S. Boland, "Nanoparticles: molecular targets and cell signalling," Archives of Toxicology, vol. 85, no. 7, pp. 733-741, 2011.

[37] I. Passagne, M. Morille, M. Rousset, I. Pujalté, and B. L'azou, "Implication of oxidative stress in size-dependent toxicity of silica nanoparticles in kidney cells," Toxicology, vol. 299, no. 2-3, pp. 112-124, 2012.

[38] R. Loperena and D. G. Harrison, "Oxidative stress and hypertensive diseases," The Medical Clinics of North America, vol. 101, no. 1, pp. 169-193, 2017.

[39] A. Gonzalez-Vicente and J. L. Garvin, "Effects of reactive oxygen species on tubular transport along the nephron," Antioxidants, vol. 6, no. 2, p. 23, 2017.

[40] A. Thit, H. Selck, and H. F. Bjerregaard, "Toxic mechanisms of copper oxide nanoparticles in epithelial kidney cells," Toxicology In Vitro, vol. 29, no. 5, pp. 1053-1059, 2015.

[41] I. Pujalté, I. Passagne, B. Brouillaud et al., "Cytotoxicity and oxidative stress induced by different metallic nanoparticles on human kidney cells," Particle and Fibre Toxicology, vol. 8, no. 1, p. 10, 2011.

[42] V. G. Reshma and P. V. Mohanan, "Cellular interactions of zinc oxide nanoparticles with human embryonic kidney (HEK 293) cells," Colloids and Surfaces B: Biointerfaces, vol. 157, pp. 182-190, 2017.

[43] V. L. Colvin, "The potential environmental impact of engineered nanomaterials," Nature Biotechnology, vol. 21, no. 10, pp. 1166-1170, 2003.

[44] M. A. K. Abdelhalim and B. M. Jarrar, "Renal tissue alterations were size-dependent with smaller ones induced more effects and related with time exposure of gold nanoparticles," Lipids in Health and Disease, vol. 10, no. 1, p. 163, 2011.

[45] D. Arora, V. Dhanwal, D. Nayak et al., "Preparation, characterization and toxicological investigation of copper loaded chitosan nanoparticles in human embryonic kidney HEK293 cells," Materials Science \& Engineering C: Materials for Biological Applications, vol. 61, pp. 227-234, 2016.

[46] K. Sooklert, S. Chattong, K. Manotham et al., "Cytoprotective effect of glutaraldehyde erythropoietin on HEK293 kidney cells after silver nanoparticle exposure," International Journal of Nanomedicine, vol. 11, pp. 597-605, 2016.

[47] S. J. Kang, Y. J. Lee, E. K. Lee, and M. K. Kwak, "Silver nanoparticles-mediated G2/M cycle arrest of renal epithelial cells is associated with NRF2-GSH signaling," Toxicology Letters, vol. 211, no. 3, pp. 334-341, 2012.

[48] G. Wolf, S. Chen, and F. N. Ziyadeh, "From the periphery of the glomerular capillary wall toward the center of disease: podocyte injury comes of age in diabetic nephropathy," Diabetes, vol. 54, no. 6, pp. 1626-1634, 2005.

[49] P. Xu, J. Xu, S. Liu, and Z. Yang, "Nano copper induced apoptosis in podocytes via increasing oxidative stress," Journal of Hazardous Materials, vol. 241-242, pp. 279-286, 2012.

[50] S. V. Shah, R. Baliga, M. Rajapurkar, and V. A. Fonseca, "Oxidants in chronic kidney disease," Journal of the American Society of Nephrology, vol. 18, no. 1, pp. 16-28, 2007.

[51] S. Altenhöfer, P. W. M. Kleikers, K. A. Radermacher et al., "The NOX toolbox: validating the role of NADPH oxidases in physiology and disease," Cellular and Molecular Life Sciences, vol. 69, no. 14, pp. 2327-2343, 2012.
[52] J. Xu, Z. Li, P. Xu, L. Xiao, and Z. Yang, "Nanosized copper oxide induces apoptosis through oxidative stress in podocytes," Archives of Toxicology, vol. 87, no. 6, pp. 1067-1073, 2013.

[53] T. M. Potter, B. W. Neun, and S. T. Stern, "Assay to detect lipid peroxidation upon exposure to nanoparticles," Methods in Molecular Biology, vol. 697, pp. 181-189, 2011.

[54] R. Medzhitov, "Inflammation 2010: new adventures of an old flame," Cell, vol. 140, no. 6, pp. 771-776, 2010.

[55] L. Ferrero-Miliani, O. H. Nielsen, P. S. Andersen, and S. E. Girardin, "Chronic inflammation: importance of NOD2 and NALP3 in interleukin-1 $\beta$ generation," Clinical and Experimental Immunology, vol. 147, no. 2, pp. 227-235, 2007.

[56] T. Lawrence, "The nuclear factor NF- $\kappa$ B pathway in inflammation," Cold Spring Harbor Perspectives in Biology, vol. 1, no. 6, article a001651, 2009.

[57] M. A. Dobrovolskaia and S. E. McNeil, "Immunological properties of engineered nanomaterials," Nature Nanotechnology, vol. 2, no. 8, pp. 469-478, 2007.

[58] B. Sun, X. Wang, Z. Ji, R. Li, and T. Xia, "NLRP3 inflammasome activation induced by engineered nanomaterials," Small, vol. 9, no. 9-10, pp. 1595-1607, 2013.

[59] L. Chen, H. Deng, H. Cui et al., "Inflammatory responses and inflammation-associated diseases in organs," Oncotarget, vol. 9, no. 6, pp. 7204-7218, 2018.

[60] C. Sassy-Prigent, D. Heudes, C. Mandet et al., "Early glomerular macrophage recruitment in streptozotocin-induced diabetic rats," Diabetes, vol. 49, no. 3, pp. 466-475, 2000.

[61] D. L. Coleman and C. Ruef, "Interleukin-6: an autocrine regulator of mesangial cell growth," Kidney International, vol. 41, no. 3, pp. 604-606, 1992.

[62] N. Koike, T. Takamura, and S. Kaneko, "Induction of reactive oxygen species from isolated rat glomeruli by protein kinase $\mathrm{C}$ activation and TNF- $\alpha$ stimulation, and effects of a phosphodiesterase inhibitor," Life Sciences, vol. 80, no. 18, pp. 1721-1728, 2007.

[63] S. Girard, H. Kadhim, M. Roy et al., "Role of perinatal inflammation in cerebral palsy," Pediatric Neurology, vol. 40, no. 3, pp. 168-174, 2009.

[64] R. Tiwari, R. D. Singh, H. Khan et al., "Oral subchronic exposure to silver nanoparticles causes renal damage through apoptotic impairment and necrotic cell death," Nanotoxicology, vol. 11, no. 5, pp. 671-686, 2017.

[65] O. S. Adeyemi, I. Adewumi, and T. O. Faniyan, "Silver nanoparticles influenced rat serum metabolites and tissue morphology," Journal of Basic and Clinical Physiology and Pharmacology, vol. 26, no. 4, pp. 355-361, 2015.

[66] Q. Qian, "Inflammation: a key contributor to the genesis and progression of chronic kidney disease," Contributions to Nephrology, vol. 191, pp. 72-83, 2017.

[67] S. De Rechter, J. P. Decuypere, E. Ivanova et al., "Autophagy in renal diseases," Pediatric Nephrology, vol. 31, no. 5, pp. 737-752, 2016.

[68] A. M. Choi, S. W. Ryter, and B. Levine, "Autophagy in human health and disease," The New England Journal of Medicine, vol. 368, no. 7, pp. 651-662, 2013.

[69] A. Sureshbabu, S. W. Ryter, and M. E. Choi, "Oxidative stress and autophagy: crucial modulators of kidney injury," Redox Biology, vol. 4, pp. 208-214, 2015. 
[70] S. Ghavami, S. Shojaei, B. Yeganeh et al., "Autophagy and apoptosis dysfunction in neurodegenerative disorders," Progress in Neurobiology, vol. 112, pp. 24-49, 2014.

[71] B. Hartleben, N. Wanner, and T. B. Huber, "Autophagy in glomerular health and disease," Seminars in Nephrology, vol. 34, no. 1, pp. 42-52, 2014.

[72] X. Zhang, H. Yin, Z. Li, T. Zhang, and Z. Yang, "Nano- $\mathrm{TiO}_{2}$ induces autophagy to protect against cell death through antioxidative mechanism in podocytes," Cell Biology and Toxicology, vol. 32, no. 6, pp. 513-527, 2016.

[73] A. Kermanizadeh, S. Vranic, S. Boland et al., "An in vitroassessment of panel of engineered nanomaterials using a human renal cell line: cytotoxicity, pro-inflammatory response, oxidative stress and genotoxicity," BMC Nephrology, vol. 14, no. 1, p. 96, 2013.

[74] S. Kume and D. Koya, "Autophagy: a novel therapeutic target for diabetic nephropathy," Diabetes and Metabolism Journal, vol. 39, no. 6, pp. 451-460, 2015.

[75] Y. Liu, J. Zhuang, X. Zhang et al., "Autophagy associated cytotoxicity and cellular uptake mechanisms of bismuth nanoparticles in human kidney cells," Toxicology Letters, vol. 275, pp. 39-48, 2017.

[76] Y. Liu, H. Yu, X. Zhang et al., “The protective role of autophagy in nephrotoxicity induced by bismuth nanoparticles through AMPK/mTOR pathway," Nanotoxicology, vol. 12, no. 6, pp. 586-601, 2018.

[77] M. A. K. Abdelhalim and B. M. Jarrar, "The appearance of renal cells cytoplasmic degeneration and nuclear destruction might be an indication of GNPs toxicity," Lipids in Health and Disease, vol. 10, no. 1, p. 147, 2011.

[78] F. Ding, Y. Li, J. Liu et al., "Overendocytosis of gold nanoparticles increases autophagy and apoptosis in hypoxic human renal proximal tubular cells," International Journal of Nanomedicine, vol. 9, pp. 4317-4330, 2014.

[79] Y. F. Lin, I. J. Chiu, F. Y. Cheng et al., "The role of hypoxiainducible factor- $1 \alpha$ in zinc oxide nanoparticle-induced nephrotoxicity in vitro and in vivo," Particle and Fibre Toxicology, vol. 13, no. 1, p. 52, 2016.

[80] G. L. Semenza and G. L. Wang, "A nuclear factor induced by hypoxia via de novo protein synthesis binds to the human erythropoietin gene enhancer at a site required for transcriptional activation," Molecular and Cellular Biology, vol. 12, no. 12, pp. 5447-5454, 1992.

[81] Y. C. Cheng, J. M. Chang, C. A. Chen, and H. C. Chen, "Autophagy modulates endoplasmic reticulum stress-induced cell death in podocytes: a protective role," Experimental Biology and Medicine, vol. 240, no. 4, pp. 467-476, 2015.

[82] X. Zhang, H. Zhang, X. Liang et al., "Iron oxide nanoparticles induce Autophagosome accumulation through multiple mechanisms: lysosome impairment, mitochondrial damage, and ER stress," Molecular Pharmaceutics, vol. 13, no. 7, pp. 2578-2587, 2016.

[83] Z. Li, A. H. Pearlman, and P. Hsieh, "DNA mismatch repair and the DNA damage response," DNA Repair, vol. 38, pp. 94-101, 2016.

[84] S. P. Jackson and J. Bartek, "The DNA-damage response in human biology and disease," Nature, vol. 461, no. 7267, pp. 1071-1078, 2009.

[85] M. Yan, C. Tang, Z. Ma, S. Huang, and Z. Dong, "DNA damage response in nephrotoxic and ischemic kidney injury," Toxicology and Applied Pharmacology, vol. 313, pp. 104-108, 2016.
[86] H. J. Johnston, G. Hutchison, F. M. Christensen, S. Peters, S. Hankin, and V. Stone, "A review of the in vivo and in vitro toxicity of silver and gold particulates: particle attributes and biological mechanisms responsible for the observed toxicity," Critical Reviews in Toxicology, vol. 40, no. 4, pp. 328-346, 2010.

[87] M. Ahamed, M. Karns, M. Goodson et al., "DNA damage response to different surface chemistry of silver nanoparticles in mammalian cells," Toxicology and Applied Pharmacology, vol. 233, no. 3, pp. 404-410, 2008.

[88] P. V. AshaRani, G. Low Kah Mun, M. P. Hande, and S. Valiyaveettil, "Cytotoxicity and genotoxicity of silver nanoparticles in human cells," ACS Nano, vol. 3, no. 2, pp. 279290, 2009.

[89] S. A. Stewart and R. A. Weinberg, "Telomeres: cancer to human aging," Annual Review of Cell and Developmental Biology, vol. 22, pp. 531-557, 2006.

[90] R. Meena, M. Rani, R. Pal, and P. Rajamani, "Nano- $\mathrm{TiO}_{2}$ induced apoptosis by oxidative stress-mediated DNA damage and activation of p53 in human embryonic kidney cells," Applied Biochemistry and Biotechnology, vol. 167, no. 4, pp. 791-808, 2012.

[91] E. Demir, H. Akça, F. Turna et al., "Genotoxic and celltransforming effects of titanium dioxide nanoparticles," Environmental Research, vol. 136, pp. 300-308, 2015.

[92] G. M. Morsy, K. S. El-Ala, and A. A. Ali, "Studies on fate and toxicity of nanoalumina in male albino rats: lethality, bioaccumulation and genotoxicity," Toxicology and Industrial Health, vol. 32, no. 2, pp. 344-359, 2016.

[93] F. Wang, F. Gao, M. Lan, H. Yuan, Y. Huang, and J. Liu, "Oxidative stress contributes to silica nanoparticle-induced cytotoxicity in human embryonic kidney cells," Toxicology In Vitro, vol. 23, no. 5, pp. 808-815, 2009.

[94] D. P. DiRocco, J. Bisi, P. Roberts et al., "CDK4/6 inhibition induces epithelial cell cycle arrest and ameliorates acute kidney injury," American Journal of Physiology-Renal Physiology, vol. 306, no. 4, pp. F379-F388, 2014.

[95] D. A. Ferenbach and J. V. Bonventre, "Mechanisms of maladaptive repair after AKI leading to accelerated kidney ageing and CKD," Nature Reviews Nephrology, vol. 11, no. 5, pp. 264-276, 2015.

[96] L. Yang, T. Y. Besschetnova, C. R. Brooks, J. V. Shah, and J. V. Bonventre, "Epithelial cell cycle arrest in G2/M mediates kidney fibrosis after injury," Nature Medicine, vol. 16, no. 5, pp. 535-543, 2010.

[97] N. K. Uzar, M. Abudayyak, N. Akcay, G. Algun, and G. Özhan, "Zinc oxide nanoparticles induced cyto- and genotoxicity in kidney epithelial cells," Toxicology Mechanisms and Methods, vol. 25, no. 4, pp. 334-339, 2015.

[98] M. T. Ortega, J. E. Riviere, K. Choi, and N. A. Monteiro-Riviere, "Biocorona formation on gold nanoparticles modulates human proximal tubule kidney cell uptake, cytotoxicity and gene expression," Toxicology In Vitro, vol. 42, pp. 150-160, 2017.

[99] F. A. Valentijn, L. L. Falke, T. Q. Nguyen, and R. Goldschmeding, "Cellular senescence in the aging and diseased kidney," Journal of Cell Communication and Signaling, vol. 12, no. 1, pp. 69-82, 2018.

[100] H. Stopper, F. Boullay, A. Heidland, J. Vienken, and U. Bahner, "Comet-assay analysis identifies genomic damage in lymphocytes of uremic patients," American Journal of Kidney Diseases, vol. 38, no. 2, pp. 296-301, 2001. 
[101] C. Ersson, R. Thorman, Y. Rodhe, L. Möller, and B. Hylander, "DNA damage in salivary gland tissue in patients with chronic kidney disease, measured by the comet assay," Oral Surgery, Oral Medicine, Oral Pathology, Oral Radiology, and Endodontics, vol. 112, no. 2, pp. 209-215, 2011.

[102] A. Christensson, C. Savage, D. D. Sjoberg et al., “Association of cancer with moderately impaired renal function at baseline in a large, representative, population-based cohort followed for up to 30 years," International Journal of Cancer, vol. 133, no. 6, pp. 1452-1458, 2013.

[103] G. Wong, A. Hayen, J. R. Chapman et al., "Association of $\mathrm{CKD}$ and cancer risk in older people," Journal of the American Society of Nephrology, vol. 20, no. 6, pp. 13411350, 2009.

[104] C. N. Young, "Endoplasmic reticulum stress in the pathogenesis of hypertension," Experimental Physiology, vol. 102, no. 8, pp. 869-884, 2017.

[105] J. G. Dickhout and J. C. Krepinsky, "Endoplasmic reticulum stress and renal disease," Antioxidants \& Redox Signaling, vol. 11, no. 9, pp. 2341-2352, 2009.

[106] C. Hetz, "The unfolded protein response: controlling cell fate decisions under ER stress and beyond," Nature Reviews Molecular Cell Biology, vol. 13, no. 2, pp. 89-102, 2012.

[107] A. S. Lee, "The glucose-regulated proteins: stress induction and clinical applications," Trends in Biochemical Sciences, vol. 26, no. 8, pp. 504-510, 2001.

[108] R. J. Kaufman, "Orchestrating the unfolded protein response in health and disease," The Journal of Clinical Investigation, vol. 110, no. 10, pp. 1389-1398, 2002.

[109] M. Kitamura, "Endoplasmic reticulum stress in the kidney," Clinical and Experimental Nephrology, vol. 12, no. 5, article 60, pp. 317-325, 2008.

[110] A. V. Cybulsky, "Endoplasmic reticulum stress, the unfolded protein response and autophagy in kidney diseases," Nature Reviews Nephrology, vol. 13, no. 11, pp. 681-696, 2017.

[111] R. Inagi, "Endoplasmic reticulum stress in the kidney as a novel mediator of kidney injury," Nephron Experimental Nephrology, vol. 112, no. 1, pp. e1-e9, 2009.

[112] Y. Xu, M. Guo, W. Jiang et al., "Endoplasmic reticulum stress and its effects on renal tubular cells apoptosis in ischemic acute kidney injury," Renal Failure, vol. 38, no. 5, pp. 831837, 2016.

[113] L. Huo, R. Chen, L. Zhao et al., "Silver nanoparticles activate endoplasmic reticulum stress signaling pathway in cell and mouse models: the role in toxicity evaluation," Biomaterials, vol. 61, pp. 307-315, 2015.

[114] B. D. Chithrani, A. A. Ghazani, and W. C. Chan, "Determining the size and shape dependence of gold nanoparticle uptake into mammalian cells," Nano Letters, vol. 6, no. 4, pp. 662-668, 2006.

[115] M. J. Clift, S. Bhattacharjee, D. M. Brown, and V. Stone, “The effects of serum on the toxicity of manufactured nanoparticles," Toxicology Letters, vol. 198, no. 3, pp. 358-365, 2010.

[116] S. Bhattacharjee, D. Ershov, K. Fytianos et al., "Cytotoxicity and cellular uptake of tri-block copolymer nanoparticles with different size and surface characteristics," Particle and Fibre Toxicology, vol. 9, no. 1, p. 11, 2012.

[117] L. Yang, H. Kuang, W. Zhang et al., "Size dependent biodistribution and toxicokinetics of iron oxide magnetic nanoparticles in mice," Nanoscale, vol. 7, no. 2, pp. 625-636, 2015.
[118] L. Li, T. Liu, C. Fu, L. Tan, X. Meng, and H. Liu, "Biodistribution, excretion, and toxicity of mesoporous silica nanoparticles after oral administration depend on their shape," Nanomedicine, vol. 11, no. 8, pp. 1915-1924, 2015.

[119] M. Cuña, M. Alonso-Sande, C. Remuñán-López, J. P. Pivel, J. L. Alonso-Lebrero, and M. J. Alonso, "Development of phosphorylated glucomannan-coated chitosan nanoparticles as nanocarriers for protein delivery," Journal of Nanoscience and Nanotechnology, vol. 6, no. 9, pp. 2887-2895, 2006.

[120] R. Barbir, W. Goessler, M. Ćurlin et al., "Protein corona modulates distribution and toxicological effects of silver nanoparticles in vivo," Particle \& Particle Systems Characterization, vol. 36, no. 8, article 1900174, 2019. 


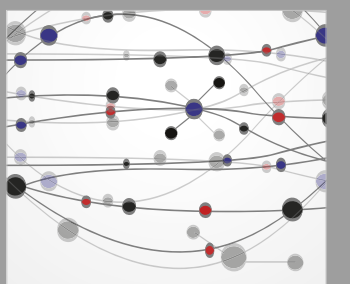

The Scientific World Journal
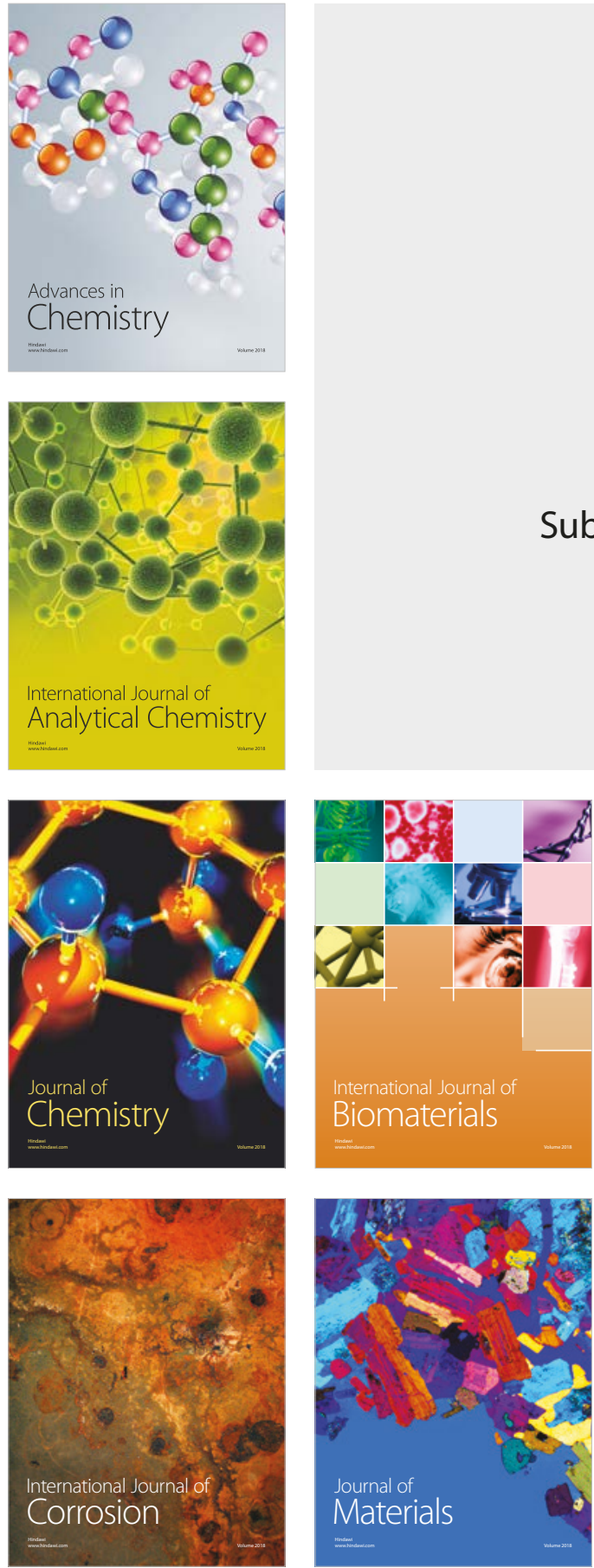

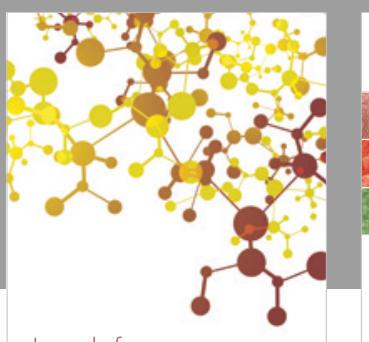

Journal of

Applied Chemistry
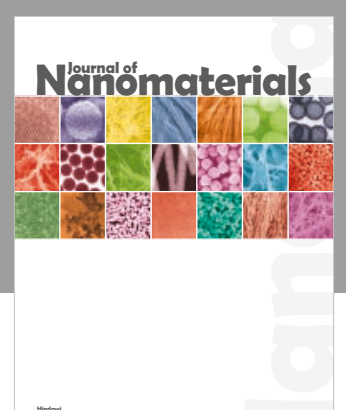

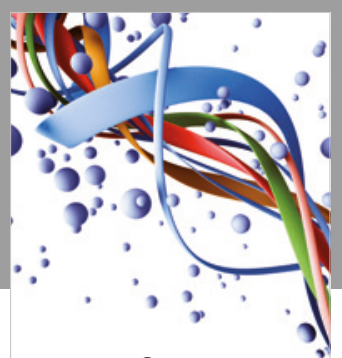

Scientifica

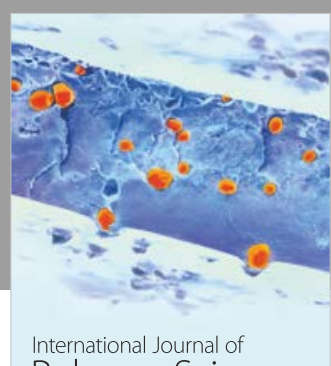

Polymer Science

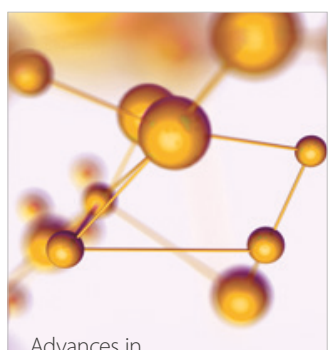

Physical Chemistry
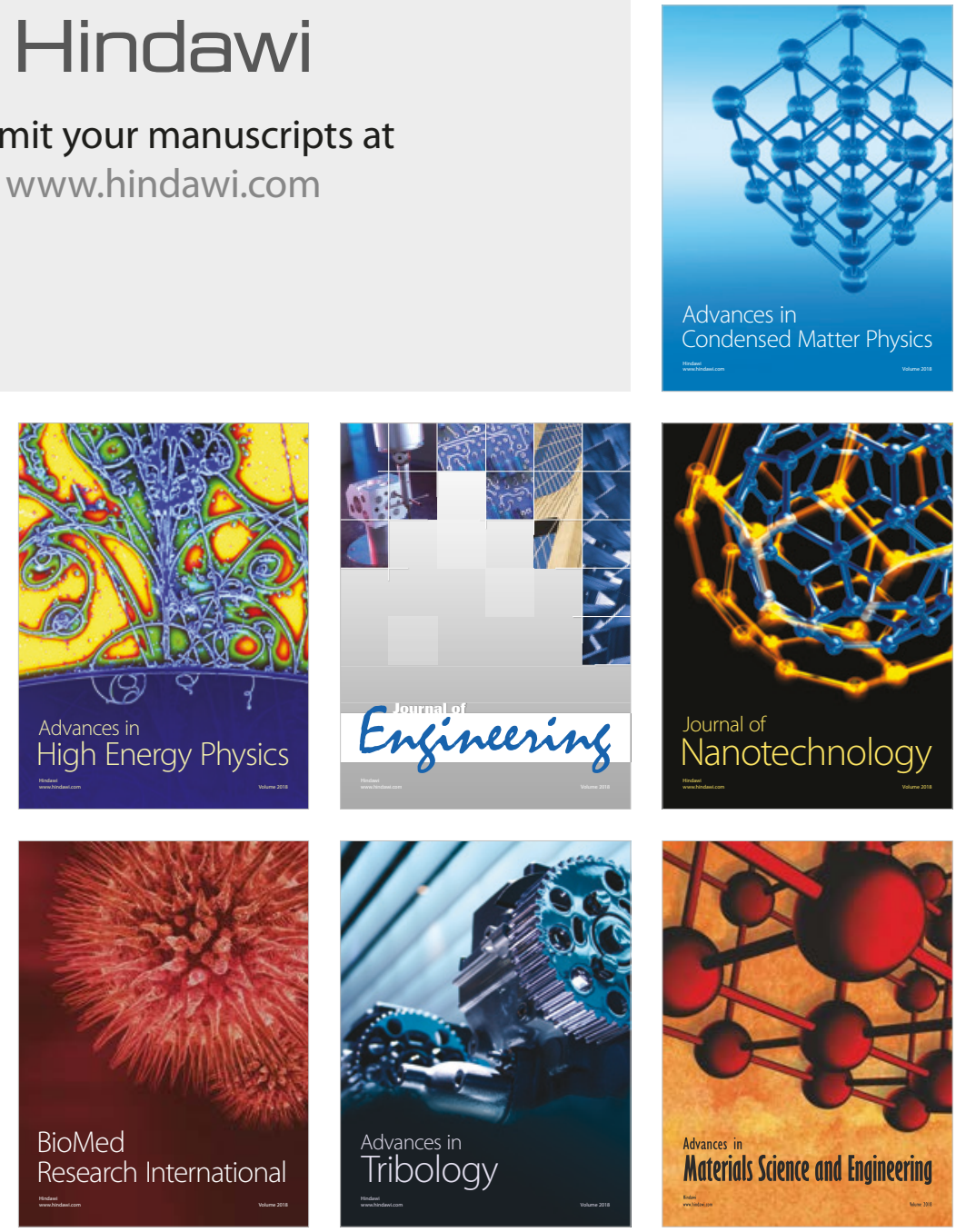